\title{
CRÍTICA Y EMANCIPACIÓN EN LOS INICIOS DE LA TEORÍA SOCIAL CONTEMPORÁNEA
}

Marlon Javier López Universidad de El Salvador javierlopezm@gmail.com

Recepción: 25 de julio de 2016 Aceptación: 12 de agosto de 2016 


\section{RESUMEN}

El artículo aborda una discusión teórica que tiene lugar a inicios del siglo XIX en Europa. A comienzos del siglo XIX surge un enconado interés por el estudio de los temas sociales en Alemania, el cual remite a una teoría social en gestación, que sienta las bases de una ulterior teoría crítica de la sociedad. Para descubrir sus huellas, se examina brevemente la Fenomenología del Espíritu de Hegel, como un momento fundamental en la conformación de esta teoría, analizando con detalle los elementos humanistas, críticos y científicos contenidos en la obra. Estos elementos nutren la posterior teoría política y social elaborada por Marx en donde el problema de la enajenación se convierte en tema central de discusión para caracterizar la sociedad contemporánea, en medio de una profunda polémica contra Hegel. A la base de todo esto se encuentra asimismo el problema de la economía política, lo que revela la naturaleza de la discusión, dirigida a criticar a la sociedad capitalista y a su superación.

\section{Palabras Clave}

Teoría social, dialéctica, enajenación, crítica social, trabajo

\section{ABSTRACT}

The article take care of the theoretical discussion that takes place in the early nineteenth century Europe. In the early nineteenth century a fierce interest in the study of social issues in Germany, which refers to a social theory in gestation, which lays the foundation for further critical theory of society emerges. To discover their tracks, the Phenomenology of Spirit Hegel briefly discussed as a pivotal moment in the formation of this theory, analyzing in detail the humanist elements , critical and scientific content in to work. These elements nourish the subsequent political and social theory developed by Marx where the problem of alienation becomes a central topic of discussion to characterize the contemporary society, amid deep polemic against Hegel. underlaying all of this, is also located the political economy knowledge, which reveals the nature of the discussion , aimed to criticize capitalist society and to overcome them.

\section{Keywords}

Social theory, alienation, social criticism, work 


\title{
CRÍTICA Y EMANCIPACIÓN EN LOS INICIOS DE LA TEORÍA SOCIAL CONTEMPORÁNEA
}

\author{
Marlon Javier López \\ Universidad de El Salvador \\ javierlopezm@gmail.com
}

\section{Introducción}

La teoría social crítica contemporánea es deudora directa de la filosofia que desde el combate político se gesta a inicios del siglo XIX en Alemania, donde brota la lógica de la negatividad de manos del más grande filósofo de la época: Hegel, pasando a continuación a formar parte esencial de la teoría política de Marx quien desde su más temprana juventud se preocupó por estudiar profundamente aquel influyente personaje, tal como lo revela uno de sus primeros escritos ${ }^{1}$, para seguir encontrando en éste, elementos importantes a tener en consideración durante toda su trayectoria intelectual. A lo largo de todo este profundo examen, Marx va señalando las conquistas y limitaciones de su antecesor. Los resultados más completos se presentan en sus Manuscritos Económico-Filosóficos de 1844, específicamente en el apartado donde presenta un balance crítico de la dialéctica y de la filosofia hegeliana en general ${ }^{2}$. Este trabajo tiene una importancia crucial, pues en él Marx deja entrever el lugar que juega dentro de sus reflexiones económicas, la lógica de la Fenomenología del espíritu.

\footnotetext{
${ }^{1}$ Carlos Marx, Escritos de juventud (México: Fondo de Cultura Económica, 1982), 11.

${ }^{2}$ Marx, Escritos de Juventud, 645-668.
} 


\section{La teoría social en la Fenomenología del espíritu de Hegel}

Para entender la riqueza de una obra como la Fenomenología del espíritu, hay que tener en cuenta dos aspectos metodológicos esenciales presentes en toda su estructura. Por un lado la deducción dialéctica de las categorías, y por otro la historicidad. En la Fenomenología, estos dos aspectos se expresan mediante la articulación de los múltiples momentos históricos y las distintas etapas del espíritu (certeza sensible, percepción, entendimiento, razón, espíritu, etc.) de tal modo que el camino señalado por estas etapas "aparenta ser un camino psicológico", pero es "al mismo tiempo un camino histórico y hasta natural, todo eso entrelazado"

Esta unidad lógico-metodológica encuentra un lugar común en toda la obra. En ella es perceptible la múltiple articulación de las distintas partes en un todo dialéctico. La obra, como se ha señalado en repetidas ocasiones, posee dos sentidos: por un lado trazar el modo de asenso desde la conciencia común al saber absoluto, es decir hasta la "ciencia" y por otro lado exponer el recorrido histórico de la humanidad hasta este saber. El resultado es el reconocimiento de la historia como un autorrealizarse de la humanidad. Como se sabe, Marx ha sido el primero en reconocer este hecho ${ }^{4}$.

Este resultado sigue una lógica rigurosa de exposición. Es un producto derivado del proceso mismo del saber que se realiza. Al principio se muestra como un destino fatal que ocurre al margen de la voluntad individual excluida del proceso. El análisis de los diversos momentos mostrará posteriormente cómo y de qué manera este constituye realmente una progresión social que involucra la práctica colectiva de toda la historia humana. La conciencia se transforma en razón, capaz de apropiarse la totalidad de las experiencias humanas, remontándose hasta el saber absoluto.

Es este uno de los principales propósitos de la obra. El recorrido de ascenso desde la conciencia común hasta la ciencia es, al mismo tiempo, el

\footnotetext{
${ }^{3}$ Ernst Bloch, Sujeto-objeto: El pensamiento de Hegel (México: Fondo de Cultura Económica, 1982), 60 .

${ }^{4}$ Carlos Marx, Obras de Marx y Engels, OME V. 5 (Barcelona: Editorial Crítica, 1978), 417.
} 
recorrido de la humanidad a través de su historia. La obra posee por tanto un fin pedagógico. Hippolite ha señalado la posible influencia del Emilio, el gran tratado pedagógico de Rousseau, lo cual es otra muestra de los ideales emancipadores que Hegel compartía con los ilustrados ${ }^{5}$.

A continuación, haremos un breve esbozo sobre la forma en la cual Hegel señala este recorrido que ha de conducir hasta la verdadera ciencia, el "saber absoluto". Para ello es necesaria una exposición siquiera breve de la obra.

Los primeros capítulos de la obra (I-V) se ocupan de la conciencia individual, en su desarrollo desde la simple intuición sensible. En esta etapa del ascenso dialéctico, el mundo objetivo suele aparecer a la conciencia como un mundo que se desarrolla al margen e independientemente de aquella. En esta interacción con un mundo desconocido, la conciencia logra paulatinamente penetrar en la esencia de la realidad.

Desde el primer momento el impulso ascendente tienen lugar gracias a las contradicciones que el pensamiento encuentra en sí mismo. De modo que la conciencia, que en primer momento aparece contrapuesta a la realidad, va permeándola progresivamente de contenido, percibiendo en un grado cada vez mayor, el carácter genérico de su actividad.

De esta manera en primera instancia la exposición adquiere un carácter dual que abarca por un lado, el movimiento autónomo del mundo como realidad enigmática frente a la conciencia que choca con él. Pero es esta tensión dialéctica de la subjetividad frente a la realidad objetiva la que la dota de un nivel cada vez mayor de captación de la misma y de sus leyes dialécticas.

Este modo de exposición hace posible iluminar la compleja relación entre la especie y el individuo, mediante el descubrimiento que tiene lugar en el movimiento inmanente de la conciencia individual. Hegel ha sentado la base de este método en el prólogo de la obra:"El conocimiento científico en cambio exige entregarse a la vida del objeto, o lo que es lo mismo, tener

\footnotetext{
5 Jean Hyppolite, Génesis y estructura de la «Fenomenología del espíritu» (Barcelona: Ediciones Península, 1974), 14.
} 
ante sí y expresar la necesidad interna de él ${ }^{6}$." Por donde quedan superadas, tanto las limitaciones subjetivas de Kant y Fichte como la concepción mecanicista de la especie propia de la ilustración. En la Fenomenología del Espíritu la conciencia individual aprende a distinguir la realidad, como derivada de sí misma. La conciencia que ahora se mueve en una realidad ajena, tratará de trasgredir los límites de la naturaleza, la razón es una razón práctica pues intenta rebasar el mero saber de lo otro, cobrando autonomía y esta autonomía se presenta en su actividad. Este es el resultado más importante de esta primera parte cuyo primer gran punto de inflexión lo constituye el pasaje del dominio y la servidumbre, donde la lucha entre el señor y el siervo termina con el autodominio del estoico libre e independiente de las circunstancias y el destino, así como en la exposición de la absoluta libertad del escéptico que se niega a reconocer cualquier otra realidad. Finalmente esta verdad es representada en la conciencia desventurada. La pura subjetividad que sufre y que no tiene ya en sí misma su propia sustancia. Este pasaje corresponde a la disolución del mundo antiguo; la conciencia desventurada corresponde al cristianismo y a la Edad Media.

Es de un profundo significado el que la superación de la inmediatez natural se produzca históricamente sólo gracias al trabajo. La noción hegeliana de que el hombre se hace hombre gracias a que introduce el trabajo entre su deseo y su satisfacción. Curiosamente el desarrollo social no se produce por obra del señor sino del siervo que trabaja. Esta concepción es común a Hegel de aquí en adelante; se repite nuevamente en la Enciclopedia ${ }^{7}$.

El siguiente punto de inflexión se encuentra en la génesis de la subjetividad revolucionaria de la modernidad, momento a partir del cual la colisión entre el individuo y la realidad, el "en sí", se presenta de manera cada vez más intensa. Varios pasajes expresan ese conflicto: el placer frente a la necesidad, la ley del corazón, la virtud que anhela mejorar el mundo pretendiendo "ser ley en sí y para sí". En consecuencia, cada uno de esos pasajes constituye una prueba de la ruina a la que llevan los diversos esfuerzos individuales frente al desconocimiento de una realidad extraña, desconocida y opuesta a ellos.

\footnotetext{
${ }^{6}$ Georg Hegel, Fenomenología del Espíritu (México: Fondo de Cultura Económica, 1966), 36.

${ }^{7}$ Georg Hegel, Enciclopedia de las Ciencias Filosóficas, (Madrid: Alianza Editorial, 1999), 479.
} 
En los diversos choques con que la individualidad se enfrenta a la realidad, va penetrando lentamente el "en sí" social hasta consumarse como "individualidad real" plasmada en "el reino animal del espíritu"; nombre con el cual Hegel identifica a la sociedad capitalista, la sociedad del egoísmo.

Se distingue ahora la real conexión del individuo y la sociedad mediante la satisfacción de sus necesidades por medio del trabajo. La problemática planteada es resuelta en la actividad económico-social. Finalmente la superación de la subjetividad ocurre en el seno de la sociedad capitalista solamente por medio del trabajo ${ }^{8}$.

Aquella verdad enunciada por Marx, a saber: el que el individuo sea "no solamente un animal social, sino un animal que sólo puede individualizarse en la sociedad", es ya comprobada por Hegel.Al respecto, Prieto explica:"se trata de la antigua concepción del hombre como ser social, antepuesta al individualismo de la edad moderna. Para Hegel como para los grandes filósofos griegos, el hombre sólo se realiza en comunidad. ${ }^{10}$ "

Esto servirá para contemplar porque ha podido el filósofo superar el subjetivismo abstracto de la moral kantiana únicamente mediante un más certero conocimiento del modo de producción capitalista y de una conciencia de la dialéctica que atraviesa la praxis individual al interior de esa sociedad. El individuo pone en juego su obrar individual, y sin darse cuenta, transforma su actividad en una actividad social. En la plena conciencia de la dialéctica de este proceso reside, por lo tanto, la superioridad de Hegel, frente a los filósofos precedentes.

El resultado de esta dialéctica es la ascensión filosófica de la conciencia; una comprensión de la objetividad social, como su objetivación. Como el campo de actividad del individuo y a su vez, fundamento y contenido de la individualidad misma. La idea del hombre como ser social es no sólo plasmada en este lugar sino desarrollada y comprobada en el rigor de la exposición, en esta idea Hegel sigue a Aristóteles ${ }^{11}$.

\footnotetext{
${ }^{8}$ Hegel, Fenomenología .., 210.

${ }^{9}$ Fernando Prieto, El Pensamiento Político de Hegel (Madrid: UPCM, 1983), 62.

${ }^{10}$ CharlesTaylor, Hegel y la sociedad moderna (México: Fondo de Cultura económica, 1983), 164.

${ }^{11}$ CharlesTaylor, Hegel y la sociedad moderna (México: Fondo de Cultura económica, 1983), 164.
} 
La actividad, explica Hegel, se entrega a la cosa, la cual encarna el trabajo del sujeto. Esto hace que los resultados objetivados de la actividad subjetiva (la cosa) sean punto de encuentro entre los múltiples esfuerzos individuales. Esta compenetración de la actividad humana deriva en la constitución de un todo social dinámico.

Con esto la exposición adquiere un sentido propiamente histórico. Se concibe la realidad humana en su desarrollo acaecido. Hegel repite el proceso ya expuesto, pero en esta ocasión desde una perspectiva más profunda; la de la historia. Las "figuras de la conciencia" aparecen ahora, como totalidades concretas que rebasan el punto de vista de la simple subjetividad, como la vida ética de todo un pueblo, como espíritus verdaderos en tanto figuras de un mundo ${ }^{12}$.

Heidegger explica esta sección como la etapa que supera el saber más relativo, el saber sin espíritu. Aparece por tanto el saber que constituye la esencia del absoluto y que es espíritu. Con esto comienza la historia absoluta del espíritu absoluto ${ }^{13}$. El volverse espíritu de la conciencia se debe entender como su conversión en sustancia. Lo que hasta ahora solamente había aparecido como pensamiento del sí mismo, aparece como una realidad verdadera que habrá de desembocar en una armoniosa utopía.

El punto histórico de partida se sitúa en el mundo grecorromano, caracterizado por ser una sociedad armónica, libre de contradicciones y de conflictos sociales. "El reino ético es así en su subsistir, un mundo inmaculado, cuya pureza no mancha ninguna escisión ${ }^{14}$." Esta armonía es rota con el desarrollo de la personalidad, la cual hace necesaria la superación de ese estadio: "El todo es un equilibrio quieto de todas las partes, y cada parte un espíritu en su propio medio que no busca su satisfacción más allá de sí, sino que la posee en sí mismo, porque él mismo es en este equilibrio con el todo."15

\footnotetext{
${ }^{12}$ Hegel, Fenomenología.., 261.

${ }^{13}$ Martin Heidegger, La fenomenología del espíritu de Hegel (Madrid: Alianza Editorial, 1992), $55-56$.

${ }^{14}$ Hegel, Fenomenología.., 272

${ }^{15}$ Hegel, Fenomenología.., 271.
} 
Al mismo tiempo Hegel reconoce en este equilibrio el aspecto dinámico que le imprimen los choques y los antagonismos de las distintas clases, asignando al Estado el papel de mantener los estamentos en armonía. Pero deja entrever los conflictos sociales internos que se desprenden de él como responsables de la disolución y del avance social: Es cierto que este equilibrio sólo puede ser un equilibrio vivo por el hecho de que nace en él la desigualdad ${ }^{16}$.

Esta universalidad se hunde, por tanto, con el desarrollo de la personalidad. Sobre este punto, Hegel vuelve a las formas de la conciencia correspondiente a la disolución del mundo antiguo. Lo importante es que la atención se fija ahora en el proceso histórico mismo, en donde estas formas de la conciencia son explicadas a partir del desarrollo del nuevo sistema de relaciones humanas aparecido, pero aún no plenamente constituido, y con el cual por eso mismo, el individuo no se logra identificar. Este nuevo poder social aparece en consecuencia, como un poder no reconocido.

Esta etapa señala una primitiva forma de enajenación, propia del periodo de decadencia de la vida pública del imperio romano. La sucesión del mundo ético aparece aquí explicada por la separación del sí mismo y de su esencia. Es esta una transformación social y espiritual que marca el paso de la antigüedad al mundo moderno, y del ciudadano a la persona privada. Poco a poco la actividad de los hombres va generando una objetividad social que cristaliza sus fuerzas vitales, estableciendo conexiones cada vez más complejas. Por esta razón Hegel presta tan poca atención al periodo que comprende la edad media, pues su exposición esencialmente busca la comprensión de la génesis y el desarrollo de la sociedad capitalista. Consecuentemente el examen pasa inmediatamente a describir las contradicciones de la nueva sociedad en gestación. El espíritu inmediato, o natural, se ha disuelto en el mundo de la persona privada. Este es el germen de la subjetividad que culmina en la Revolución Francesa. El sí mismo, evoluciona ahora en sentido inverso, y mediante su enajenación en la cultura y la civilización, se adentra en toda la realidad, la cual pasa a ser la voluntad, entendida como voluntad universal. Tiene lugar, de este modo, una reconstrucción de la sustancia espiritual antes disuelta en la personalidad. Sin embargo, no se trata de una mera restitución

${ }^{16}$ Hegel, Fenomenología.., 271-272. 
de la armoniosa sustancia ética, sino de un mundo desgarrado, que se extraña a sí mismo. El espíritu se constituye como un mundo doble, separado y contrapuesto, como una realidad separada de sí ${ }^{17}$.

La contradicción se presenta de aquí en adelante como la lucha entre el Estado y la riqueza. En esta lucha, el filósofo contempla la disputa como la lucha entre dos formas del mundo, en la que la religión aparece como expresión de un mundo caduco. Es clara la manera en la cual es plasmado el contenido revolucionario de la ilustración, así como la simpatía que Hegel muestra hacia ella. La Ilustración hace nacer el más vivo despliegue de riqueza espiritual que anuncia la Revolución. La situación previa a la conmoción social es la de la trasmutación en su contrario de la vieja forma social decadente y de su ideología.

El proceso es reconstruido mediante la evolución de las autoconciencias en la etapa de conformación de los modernos Estados burgueses. El lenguaje, en donde la enajenación se produce de un modo espiritual, permite al individuo exteriorizarse, pasando a la universalidad, dotando de este modo, de un ser espiritual al mundo de la cultura. De tal forma que el lenguaje del halago eleva la riqueza a esencialidad, mientras que el lenguaje del desgarramiento refleja la conciencia del espíritu en su propio desgarramiento. Esta conciencia desgarrada hará desembocar de aquí en adelante a la conciencia noble en el espíritu revolucionario del siglo XVIII.

Hegel concibe la enajenación como la fuerza social formadora de la cultura. Un mayor grado de enajenación, producto de un mayor desarrollo de la sociedad burguesa, produce una disolución de la inmediata unidad humana, entrando ahora en el móvil entramado dialéctico propio de las relaciones económicas del capitalismo. Al principio, la propia conciencia recibe la influencia de este fenómeno como una simple imposición externa, pero al llegar el momento, comprende la naturaleza objetiva de esta realidad y de su movimiento.

La parte de la obra consagrada a señalar "la verdad de la ilustración" constituye una exposición de la sociedad capitalista desencadenada. En la sociedad burguesa, Hegel contempla algo nuevo que supera los estadios an-

\footnotetext{
${ }^{17}$ Hegel, Fenomenología.., 288.
} 
teriores. En ella el hombre se comprende cómo ser social y lo que ya había anticipado como pensamiento, se muestra como realidad en el mundo de la utilidad. El desarrollo dialéctico ahora nos lleva a la Revolución francesa y el Terror. La libertad absoluta se arroja a la conquista del mundo sin que haya fuerza alguna que sea capaz de resistirla. Con este grado de enajenación, el espíritu puede comenzar el proceso de auto-asimilación; la trasformación de la sustancia en sujeto. En la última parte de esta sección, el espíritu se constituye como autosaber que conduce hasta la reconciliación del espíritu con el espíritu absoluto. Reconciliación que pone en evidencia las expectativas optimistas puestas por el filósofo ante el proceso de aburguesamiento de la sociedad alemana. Esta perspectiva ilusoria de una reforma social latente es otro elemento que tiene en común con los filósofos de la Ilustración. Sólo desde este punto de vista es comprensiva la discusión moral con la que se cierra esta última parte. La libertad se presenta ahora como subjetividad y Hegel nos remite de Francia a Alemania. La Revolución francesa deriva en la moral de Kant y Fichte.

En la concepción moral del mundo se conjuga la inmediatez del mundo ético y la mediación del espíritu de la cultura. Esta parte de la obra ${ }^{18}$ contiene una exposición de las aspiraciones sociales presentadas bajo el influjo del heró́smo napoleónico y los principios sociales de la ilustración. Pero Hegel carece del conocimiento real del modo de funcionamiento de la sociedad capitalista. Esta es la razón por la que ésta aparezca ante sus ojos como el advenimiento mesiánico de una reforma espiritual de dificil captación.

Los últimos capítulos de la obra contienen un recorrido retrospectivo. Hegel intenta, ejecutar un ordenamiento de la exposición histórica ya desarrollada en las anteriores secciones. Esto significa que la dialéctica del desarrollo, bajo el cual aparece orientado el proceso histórico, ha sido extraída de la misma marcha del acontecimiento.

\footnotetext{
${ }^{18}$ La rica exposición histórico-fenomenológica de Hegel desarrollada en el capítulo VI que lleva por título "El espíritu", termina con una extensa exposición polémica de la moral kantiana. Cfr., Hegel, Fenomenología.., 351-392.
} 


\section{Valoración de la Fenomenología del Espíritu de Hegel}

Queda claro que para el Hegel de la Fenomenología del Espíritu, la historia de la humanidad es también la historia de la lucha por conquistar el máximo grado de captación mental de la realidad.

Este grado supremo de conciencia es llamado por Hegel saber absoluto y contiene ya los principios metodológicos para la consideración dialéctica de la objetividad del conocimiento. La concepción fenomenológica que Hegel tiene del desarrollo de la conciencia, rompe además con el antiguo mecanicismo, según el cual el progreso es consumado como un ascenso lineal. La relación dialéctica entre verdad objetiva y saber absoluto permite exponer el desarrollo en su marcha irregular ${ }^{19}$. Esto hace comprensible el enorme papel asignado por Marx y Engels a la concepción hegeliana de los procesos sociales tal y como aparecen en la Fenomenología; el que su lógica esté constituida por una metodología que haga asequible la complejidad de los sucesos históricos y sobre todo, el más grande e importante fenómeno de la época: La Revolución Francesa.

Por otro lado, bajo esta concepción, son reconocidos los distintos ámbitos de producción espiritual en su interacción recíproca. Las conquistas intelectuales del ser humano son agrupadas bajo este enorme movimiento unitario de desarrollo, en el cual, se ha ido gestando el supremo conocimiento de la dialéctica. A diferencia de la distinción antigua entre conocimiento racional, en contraposición con el resto de las formas de captación de la realidad, en el desarrollo fenomenológico de la conciencia, cada figura asimila los resultados de la anterior, elevándolos a un nivel mayor. Por esta razón, Hegel divide los estadios del desarrollo de la conciencia en tres grandes etapas: Arte, Religión y Filosofia, reconociendo en cada uno de esos campos, la lucha de la humanidad por el dominio intelectual del universo. Por tanto, es consciente del nivel que ha significado su época en el decurso histórico y social de la especie. La época de la Revolución Francesa es la época en la cual se consuma el proceso de más grande despliegue de fuerzas vitales del

\footnotetext{
${ }^{19}$ Federico Engels, Anti-Dühring. La subversión de la ciencia por el señor Eugen Dúhring (México: Editorial Grijalbo, 1968), 9-10
} 
ser humano gracias a las cuales se vuelve capaz de recoger los frutos maduros de su propio obrar. El Saber absoluto tiene por tanto presupuestos históri$\cos ^{20}$. Señala la fase en la cual es superada la propia enajenación.

Pero la solución hegeliana a la enajenación, conlleva a la supresión de toda la objetividad. Por esta razón hace pasar su exposición por un examen de los intentos que anteceden a la unidad dialéctica, concretada en el saber absoluto. Al hacerlo, llama profundamente la atención el enorme papel otorgado a la religión. Esto se explica por la incapacidad del filósofo para comprender el contenido social real de la marcha histórica. La incapacidad de explicar este movimiento es solventada con una artificiosa creación idealistamente realizada y la religión pasa a ocupar momentáneamente el lugar destacado del que ya había sido despojada en la obra.

Hegel comienza dividiendo la religión en tres grandes grupos: la religión natural, la religión del arte y la religión revelada. Lo que ve en la religión, es una forma de relacionarse con lo absoluto. Así, en la religión natural, Dios es identificado con los objetos naturales. Es significativo que este pasaje termine con la figura del artesano y se remonte a través de ella a la religión del arte; por donde Hegel hace pasar nuevamente por la dialéctica del trabajo el aspecto positivo de superación del estado natural ${ }^{21}$.

En la religión del arte es el hombre mismo el que se reverencia, mediante la transfiguración producida por la fantasía estética. Jacques D'Honth observa que el aprecio hegeliano por la Grecia antigua se debe al amor de aquella cultura por la invención, la habilidad artesanal y en definitiva, la actividad eficaz ${ }^{22}$. Todas las religiones, tanto en las que se señala el tránsito por la religión natural y la religión del arte, elevan la conciencia y la autoconciencia al nivel del espíritu absoluto, pero esto sólo se consuma en la religión revelada. En el cristianismo, Hegel ve la forma más completa de presentar la verdad que puede alcanzarse bajo la religión, la verdad revelada.

Pero el saber profundo no le compete a la religión sino a la filosofia. Pese a todo lo que se le pudiera reconocer a la religión, nada permite

\footnotetext{
${ }^{20}$ Hyppolite, Génesis y estructura de la .., 43.

${ }^{21}$ Hegel, Fenomenología.., 408-409.

22 Jaques D'Honth, Hegel, filósofo de la historia viviente (Buenos Aires: Amorrortu editores, 1966), 267.
} 
identificarla con el supremo saber, al modo de Schelling. El espíritu es vida, tal reconocimiento es uno de los méritos más importantes de la religión. La creación, la muerte, el atravesar el propio desgarramiento sobreponiéndose a él, tal es la comprensión del proceso vivificante del absoluto en su movimiento presente en el cristianismo. El dios que se hace hombre negándose, que se sacrifica a sí mismo retornando a la unidad, es la representación en la cual se revela el absoluto al cristianismo. Pero la vía de ascenso hasta él no es la de la revelación, ni la de la fe, sino la conceptual mediada por la razón. Ninguna religión, ni aún la más completa es capaz de superar el carácter de representatividad. Esta superación sólo se logra en el conocimiento filosófico.

El contenido del análisis tiene aquí la función de exponer las verdades de la fe, a la luz de la especulación racional. El pensamiento también es vida, y como tal, tiene su muerte dentro de sí mismo: separa, analiza, distingue, asesina y luego unifica su mismo objeto y esta muerte es un paso necesario para el conocimiento. Es la fuerza de la dialéctica la que hace pasar por su propia muerte al pensamiento, sólo mediante esta destrucción se crea y alcanza el conocimiento, pues "este movimiento de las esencialidades puras constituye la naturaleza de la cientificidad en general" 23 .

Esta subordinación de la religión a la filosofia restituida al final de la obra es de un enorme significado. La filosofia conquista el saber. Es la figura del filósofo, no la del profeta la que conquista el dominio mental del mundo. Éste por tanto es secularizado. Se trata de una verdad humana, no divina. Sobre esto Kaufmann reflexiona: "La Fenomenología del espíritu termina con la muerte de Dios, con el calvario; y esta vez al «Viernes Santo especulativo» - por recordar la imagen final de «Fe y saber», publicado cinco años antesno le sigue resurrección alguna ${ }^{24}$."

Hegel estaba demasiado limitado, tanto política, como filosóficamente para reconocerlo. Sus discípulos más avanzados, lograron extraer consecuentemente estas conclusiones. La Fenomenología, dirá Marx, "encierra

\footnotetext{
23 D'Honth, Hegel, filósofo de la historia.., 25.

${ }^{24}$ Walter Kaufmann, Hegel (Madrid: Alianza Editorial, 1968), 216-217.
} 
en clave todos los elementos de la crítica, preparados y elaborados a menudo mucho más allá de lo que el mismo Hegel pensaba ${ }^{25}$."

El capítulo final sobre El Saber absoluto, constituye la total consumación de la unidad dialéctica sujeto-objeto, el fin de la duplicidad. El sí mismo se ha mostrado en las múltiples experiencias de la conciencia y de sus enajenaciones idéntico al ser. Este saber al cual ha conducido la Fenomenología nos dirige al inicio de la filosofia especulativa, de la lógica, en tanto disciplina del ser como pensamiento. Pero hemos podido ver la genialidad con la cual el gran filósofo pone ya servidos los elementos para una crítica social verdadera, en la medida en que le era posible a un pensador como él.

La Fenomenología del espíritu no muestra, por tanto, más que el movimiento dialéctico mediante el cual el espíritu [en tanto espíritu humano] aprende a conocerse a sí mismo en la riqueza del universo. Esta historia de la conciencia es la historia de su experiencia: "Este movimiento dialéctico que la conciencia lleva a cabo en sí misma, tanto en su saber cómo en su objeto, en cuanto brota ante ella el nuevo objeto verdadero, es propiamente lo que se llamará experiencia ${ }^{26}$." Es decir, la progresiva revelación y asimilación de la sustancia espiritual al sí mismo: el llegar-a-si-mismo en el devenir-se-otro del saber absoluto ${ }^{27}$. El motor de esta progresión es la desigualdad persistente entre saber y verdad. Esta contradicción, constituye según Hegel la oposición interna del concepto y es la responsable de todo el desarrollo de la historia. Tal es el lenguaje filosófico con el que expresa el real movimiento de la historia; el devenir social hasta el cese de los antagonismos de clase. Los ideales de la Revolución francesa como la libertad, la igualdad, etc., se imponen únicamente en el reino del pensamiento. Lo concebido como oposición interna del concepto, no es otra cosa más que la escisión real de la sociedad humana que se presenta bajo la división y lucha de clases a través de la historia.

Esta lucha es presentada ya a su modo como motor del desarrollo en la misma Fenomenología. Hemos visto como en momentos decisivos, Hegel llega a tener una intuición de ella, poniéndola en el centro de la discusión

\footnotetext{
${ }^{25}$ Marx, Obras de Marx.., 417.

${ }^{26}$ Hegel, Fenomenología..., 58.

${ }^{27}$ Martin Heidegger, La fenomenología del espíritu..., 53.
} 
en algunos pasajes de su obra como en el del señor y el siervo, pero que por motivos sociales por nosotros ya expuestos, ha sido incapaz de comprenderla en su verdadera naturaleza. A lo más que llega Hegel es a presentar una solución ilusoria y mistificada del problema. Concibe la superación de los antagonismos sociales como una reconciliación entre el puro pensamiento y su objeto, entre el sujeto que conoce y su conocimiento.

No obstante esta reconciliación que en Hegel no representa sino la conquista del auténtico conocimiento — de la dialéctica- es tan solo una premonición de la supresión real de la desigualdad social que atraviesa la historia, donde encontramos la insatisfacción como la fuente de su movimiento. Supresión únicamente realizable bajo el socialismo. Tal ocurre cuando interpretamos correctamente la dialéctica hegeliana, es decir, como dialéctica materialista.

Hay un paralelo entre la lógica de la Fenomenología y la lógica histórica de Marx. Lenin ha llamado la atención sobre su aplicación en el campo de la economía política ${ }^{28}$. La Fenomenología del espíritu parte de la identidad del sujeto consigo mismo, identidad que es restituida en el saber absoluto como negación de la negación. Esta identidad restituida se presenta en El Capital también como negación de la negación en la abolición de la propiedad privada, mediante la acción colectiva de los oprimidos que expropian a los expropiadores ${ }^{29}$.

\section{Alcances y limitaciones del concepto hegeliano de enajenación}

En la Fenomenología del espíritu Hegel desarrolla el importante concepto de enajenación. Este concepto le permite plasmar la dinámica del desarrollo histórico y del particular carácter social del ser humano, permitiéndole iluminar profundas conexiones propias de la actividad humana. $\mathrm{La}$ objetividad social se presenta como producto del choque de fuerzas que dan como resultado una regularidad que dirige el ordenamiento social, pero que

\footnotetext{
${ }^{28}$ Vladimir Lenin, Obras V. XLII (Moscú: Editorial Progreso, 1983), 170.

${ }^{29}$ Carlos Marx, El Capital, T. I (México: Fondo de Cultura Económica, 1999), 649.
} 
a su vez tiene su génesis en la actividad práctica de los individuos. Este fenómeno permite plantear el problema de la relación dialéctica entre la práctica humana y los objetos resultantes de la ella. Práctica que, como hemos visto, encuentra su fundamento en el trabajo. Sería un error pensar que cuando Hegel se refiere al trabajo lo hace simplemente en un sentido figurado ${ }^{30}$.

Hegel es en este sentido, "el primero en ofrecer un tratamiento filosófico a fondo de la praxis humana como actividad transformadora ${ }^{31}$." $\mathrm{Su}$ perspectiva es capaz de concebir también la propia alteración a la cual son sometidos los sujetos mediante la enajenación que se deduce de su actividad colectiva. Hegel pone en marcha el análisis social, partiendo del examen de todas formas en las que cristaliza la enajenación del individuo: la cultura, el derecho, el estado, la moral, etc. En efecto, tal y como sucede en Marx, somos capaces de comprobar el estrecho vínculo existente entre el análisis de la enajenación y del trabajo como responsables de la génesis social. Digamos en apoyo de esto que un filósofo tan ajeno a Marx como lo es Heidegger, ha sido capaz de ver esta relación:

La concepción metafisica de la esencia del trabajo ha sido pensada ya con antelación en la Fenomenología del espíritu de Hegel como el proceso que se dispone a sí mismo de la producción incondicionada, es decir, como objetivación de lo efectivamente real por parte del hombre, experimentado este como subjetividad ${ }^{32}$.

La crítica del concepto hegeliano de enajenación por parte de Marx, tiene a la base un grado de conocimiento mucho mayor de la economía capitalista. Esto no tiene nada de casual, ya hemos mencionado que en el mismo Hegel el fenómeno está estrechamente vinculado con aspectos económicos.

Es un hecho comúnmente pasado por alto que el filósofo alemán haya desarrollado su filosofia en medio del más vivo interés por conocer la composición interna del capitalismo naciente. Al respecto Rosenkranz

\footnotetext{
${ }^{30}$ Theodor Adorno, Tres estudios sobre Hegel (Madrid: Taurus Ediciones, 1974), 39.

${ }^{31}$ Adolfo Sánchez Vázquez, Filosofía de la praxis (México: Siglo XXI editores, 2003), 77.

${ }^{32}$ Martin Heidegger, Carta sobre el Humanismo (Madrid: Alianza Editorial, 2000), 54.
} 
señala que el interés de Hegel por la economía clásica data del periodo de Frankfurt, explicando así la admiración del filósofo por la sociedad inglesa, debido a que "en ningún otro país habían alcanzado el mismo grado de desarrollo las fuerzas del lucro y la propiedad" 33 . Un análisis detallado mostraría la importancia que tuvo el estudio de la economía en la formación de las categorías dialécticas en Hegel, quien como mente universal estaba al tanto de los descubrimientos científicos de su época, incluyendo por tanto, los de la economía inglesa. Aquí no podemos sin embargo más que trazar una breve descripción.

En los apuntes de los cursos que anteceden a la Fenomenología del Espíritu, se puede apreciar con la mayor pureza todas las consecuencias que extrae Hegel de sus estudios de la economía inglesa. Es interesante asimismo observar que este análisis se centra en el proceso del trabajo. Hegel, bajo el influjo de Adam Smith, concibe el trabajo como modo central de la actividad humana, mediante la cual se consuma la identidad del individuo y el medio.

En la Fenomenología hemos visto como se hace pasar la superación de la etapa natural por el trabajo del esclavo. Aquí vemos como Hegel formula con mayor detalle ese proceso. La inmediatez natural, etapa que Hegel llama: La noche de la custodia, es superada por el trabajo, identificado primeramente con la actividad insensorial del lenguaje: "Este trabajo, por consiguiente, es la primera operación interna sobre sí mismo, una ocupación totalmente insensorial y el comienzo de la libre ascensión del espíritu, pues aquí se tiene a sí mismo por objeto ${ }^{34}$." Pero lleva en sí ya el momento activo de la producción: "Esta ocupación consigo consiste precisamente en producirse ${ }^{35}$."

Más adelante Hegel rebasa esta actividad ficticia, estableciendo una real, y hace de la producción de objetos, la actividad central mediante la cual el sujeto supera la simple individualidad ${ }^{36}$.

Mediante el movimiento de los múltiples momentos de la generalidad que Hegel concibe como mediación entre la coseidad, el ser-otro, y la

\footnotetext{
33 Georg Hegel, Escritos de juventud (Madrid: Fondo de Cultura Económica, 1978), 257.

${ }^{34}$ Georg Hegel, Filosofía Real (Madrid: Fondo de Cultura Económica, 2006), 160.

${ }^{35}$ Hegel, Filosofía Real.., 161.

${ }^{36}$ Hegel, Filosofía Real.., 169.
} 
subjetividad; tiene lugar la deducción de las categorías dialécticas. Así gracias a la actividad mediada por la herramienta, tiene lugar una dialéctica entre los fines y los medios, en la cual se supera la antigua oposición caracterizada por la supremacía de los fines sobre los medios $^{37}$.

Sabemos el importante lugar que ha conferido Hegel durante toda su vida a la dialéctica de los fines y los medios en su filosofía de la historia. Es curioso encontrar aquí el desarrollo de estas categorías a la luz de consideraciones económicas. Es parte de la mistificación a la que Hegel debe recurrir a la hora de explicar importantes fenómenos sociales lo que lo ha llevado a hipostasiar el sentido teleológico del trabajo a la historia. Sabemos asimismo que la noción es común en su pensamiento a lo largo de toda su vida. En la lógica encontramos nuevamente esta dialéctica. Ahí el fin se relega a segundo plano, por debajo del medio, y el contenido económico de la reflexión se muestra con total claridad:"El instrumento de trabajo se conserva, mientras los servicios inmediatos perecen y quedan olvidados. En sus utensilios el hombre posee su poder sobre la naturaleza exterior aunque se halle sometido más bien a esta para sus fines ${ }^{38}$."

Esta misma actividad que tiene lugar en el trabajo, hace posible superar la polarización entre lo contingente y lo necesario; pues por medio de la actividad ejecutada el hombre es capaz de dictar sus propios fines a la actividad meramente ciega de la naturaleza. El hombre se convierte en la razón que guía a la naturaleza, como universalidad se erige en destino de lo singular ${ }^{39}$.

Por lo tanto el análisis del trabajo ligado a los medios de producción permite comprender el sentido dialéctico de la sociedad capitalista, cuyo derivado es la propia vinculación entre los muchos individuos que satisfacen sus necesidades en el ámbito social, a la vez que se crea un determinado orden, cuya legalidad brota de los diversos esfuerzos individuales; un cuadro social móvil que se autoproduce ${ }^{40}$.

Ya desde sus inicios el concepto ha sido abordado ampliamente por Marx en estrecha vinculación con sus estudios económicos. Herbert Mar-

\footnotetext{
${ }^{37}$ Hegel, Filosofía Real..,169.

${ }^{38}$ Georg Hegel, Ciencia de la lógica (Buenos Aires: Solar/Hachette, 1968), 658.

${ }^{39}$ Hegel, Filosofía Real.., 170

${ }^{40}$ Hegel, Ciencia de la lógica.., 183-184.
} 
cuse sostiene que este concepto es el que le hace vincular la economía con la filosofia de $\mathrm{Hegel}^{41}$. Pero tampoco debemos pasar por alto el que Hegel mismo lo ha desarrollado bajo el influjo de la economía clásica, la cual ya se había ocupado de él. Por otro lado, como bien señala Löwy, su profundo análisis a propósito de la economía habría sido decisivo en la configuración de su concepción del mundo, conduciéndolo a su adhesión definitiva al comunismo $^{42}$. Es cierto que al criticar la Filosofia del derecho de Hegel ya ha podido discutir sobre este concepto, pero es sólo a raíz del análisis económico que dicha crítica adquiere el nivel de una teoría general que posibilite la comprensión de la economía, de la totalidad del cuadro social del capitalismo y de sus consecuencias para la entera vida humana.

\section{Crítica filosófica y social en Marx}

Marx parte del hecho de que la división del trabajo en la sociedad capitalista trae consigo la completa pérdida del ser humano, primero como trabajador y posteriormente como género; el trabajo bajo el capitalismo es, por tanto, la completa enajenación de la especie humana en tanto situación en la que olvidamos que también la historia es producto nuestro dejándonos dominar por ella como si se tratara de una fuerza ajena ${ }^{43}$.

El primer punto de coincidencia con Hegel es que concibe al trabajo como la actividad originaria de la praxis humana. El carácter específico del ser humano consiste en que es un ser que se realiza por medio del trabajo ${ }^{44}$. Marx considera que una de las cualidades más importantes del ser humano consiste en la propia producción práctica del mundo objetivo ${ }^{45}$. No sólo la especie humana es capaz de producir, también el animal, "se hace su nido o construye viviendas, como las abejas, castores, hormigas, etc. ${ }^{46}$ ", pero

\footnotetext{
${ }^{41}$ Herbert Marcuse, Razón y revolución (Madrid: Ediciones Altaya, 1994), 268.

42 Michael Löwy, La teoría de la revolución en el joven Marx, (Buenos Aires: Siglo XXI editores, 1972), 134.

43 Terry Eagleton, Por qué Marx tenía razón (Barcelona: Ediciones Península, 2011), 134.

${ }^{44}$ Marx, Obras de Marx.., 354-355.

45 Marx, Obras de Marx.., 355.

${ }^{46}$ Marx, Obras de Marx.., 355.
} 
la diferencia es que sólo el hombre produce libremente, sobreponiéndose a la necesidad natural. Esta noción le será común a lo largo de toda la vida. Se repite nuevamente en el capital ${ }^{47}$. De este modo lo que en Hegel se presenta de manera mistificada como la elaboración inconsciente de su mundo por la especie humana y posterior apropiación por parte del espíritu, aparece aquí en Marx depurado de los elementos místicos. Haciendo esta importantísima distinción, podemos percibir como el análisis se orienta en la misma dirección.

Pero la inversión que tiene lugar en el seno de la sociedad capitalista hace del trabajo algo completamente diferente. Marx ha plasmado con la mayor y más profunda viveza, el absoluto desgarramiento que sufre el ser humano bajo la división del trabajo propia de la sociedad capitalista. Este desgarramiento se funda desde el momento mismo en que el trabajo deja de ser una necesidad, constituyéndose como un simple medio para la satisfacción de otras necesidades; todas las consecuencias se hallan encerradas en el hecho de que el producto de su trabajo sea para el trabajador un objeto ajeno ${ }^{48}$. Tal hecho es posible porque la sociedad capitalista se asienta sobre la absoluta división entre los medios de trabajo y el propio trabajador, el cual se encuentra así enajenado, tanto de los medios necesarios para realizar su actividad como de los mismos resultados objetivados de su propio trabajo. Finalmente el trabajador se enajena a sí mismo ${ }^{49}$.

Las consecuencias que presenta la enajenación del trabajo en el capitalismo trascienden al puro individuo, penetran la totalidad de la realidad del todo social; primero cuando separa la vida de la especie de la del individuo, convirtiendo la vida individual en un simple medio para el mantenimiento de esta totalidad abstraída del sujeto. Luego cuando al separarlo de su propio cuerpo y de su propia humanidad lo enajena del resto de los hombres. Esta base es pues, el fundamento material, el ser social de donde brota la existencia de todos los valores anti humanistas propios de la sociedad capitalista $^{50}$. Es asimismo la base de la noción de trabajo concebido como

\footnotetext{
${ }^{47}$ Marx, El Capital.., 130-131.

${ }^{48}$ Marx, El Capital.., 350.

${ }^{49}$ Marx, El Capital.., 351-352

${ }^{50}$ Marx, El Capital.., 356.
} 
sacrificio presente en la economía clásica, en oposición a la plena libertad identificada con el descanso; a esa noción ahistórica Marx contraponía su propia concepción dialéctica e histórica:

¡Trabajarás con el sudor de tu frente! fue la maldición que Jehová lanzó sobre Adam.Y de esta suerte, como maldición, concibe A. Smith el trabajo. El "reposo" aparece como el estado adecuado, como idéntico a la libertad, a la "dicha”. Que el individuo "en su estado norma de salud, vigor, actividad, habilidad, destreza," tenga también la necesidad de su porción normal de trabajo, y de la supresión del reposo parece estar muy lejos de su pensamiento $[\ldots]^{51}$

Y sobre esta base Marx reflexiona en términos muy parecidos a como lo había hecho en 1844 e incluso a los pasajes de Hegel citados por nosotros hace apenas un momento:

A no dudarlo, la medida misma del trabajo se presenta como dada exteriormente, por medio del objetivo a alcanzar y de los obstáculos que el trabajo debe superar para su ejecución. Pero que esta superación de obstáculos es de por sí ejercicio de la libertad -y que además a los objetivos exteriores se les haya despojado de la experiencia de necesidad natural meramente exterior, y se les haya puesto como objetivos que no es sino el individuo mismo el que los pone, o sea como autorrealización, objetivación del sujeto, por ende libertad real cuya acción es precisamente el trabajo [de todo esto] A. Smith no abriga la menor sospecha ${ }^{52}$.

Apreciamos así, cómo lo que Hegel ha formulado como el comienzo de la libre ascensión del espíritu, Marx lo ha determinado como la acción de la libertad real bajo un lenguaje más concreto y explícito, dejando claro el que esta concepción sea propia de una determinada formación histórico-social caracterizada por la división social del trabajo y la real subordinación del trabajador sobre el propietario de los medios de producción.

\footnotetext{
${ }^{51}$ Marx, Elementos Fundamentales para la crítica de la economía Política, Volumen 2..., 119.

${ }^{52}$ Marx, Elementos Fundamentales.., 119.
} 
Por tanto, la enajenación del trabajo es el punto de partida para lo que Marx posteriormente, en el capital, llamará fetichismo de la mercancía, que no consiste sino en el hecho de que las relaciones sociales del ser humano aparezcan ante los ojos de las personas como relaciones fantasmagóricas entre las $\cos ^{5}{ }^{53}$.

\section{Conclusión}

La teoría madura del Marx del capital encuentra fundamento teórico, a la luz de la discusión entablada con Hegel en torno al concepto de enajenación. Con estos elementos podemos concretizar en la crítica de Marx hacia la teoría de la enajenación tal y como se encuentra presente en la Fenomenología del espíritu. Comencemos recordando que Hegel ha visto en este fenómeno la forma esencial mediante la cual el individuo penetra en formas cada vez más complejas de la realidad; que el resultado de esa penetración no es otro sino el de la individualidad auto-reconocida en los resultados objetivados de su propia actividad y que culmine, para utilizar una expresión del mismo Hegel, con el hundimiento de la autoconciencia en sí misma.

Marx señala el error fundamental en Hegel al no saber diferenciar el extrañamiento del hombre en una realidad configurada por él. La supresión de la enajenación conlleva por tanto, para él, la anulación de la realidad sensible. En su crítica hacia el capítulo del saber absoluto, Marx opone a la teoría hegeliana de la superación de la objetividad su propia teoría materialista de la objetividad ${ }^{54}$.

Sin embargo, para Hegel de lo que se trata es de suprimir la exterioridad completa mediante la cual se pone fuera de sí en su actividad el individuo, precisamente por ser una realidad opuesta al pensamiento. El hecho mismo de que haya cosas, en ya en Hegel, producto del extrañamiento ${ }^{55}$. Por tanto Hegel soterra todos los aspectos críticos contenidos en la Fenomenología del espíritu, teniendo ya presentes todos los aspectos "conservadores" que

\footnotetext{
${ }^{53}$ Marx, El Capital.., 38.

${ }^{54}$ Marx, Obras de Marx.., 420.

${ }^{55}$ Marx, Obras de Marx.., 416.
} 
Hegel desarrollará en posteriores obras ${ }^{56}$. Sin embargo, contiene al mismo tiempo los elementos para una ulterior y más completa crítica de todo lo existente ${ }^{57}$.

Hemos expuesto la forma específicamente mistificada bajo la cual se lleva a cabo la supresión de la objetividad en la parte final de la Fenomenología.Aquí solo se trataba de señalar el modo particular mediante el cual Marx, partiendo del más profundo conocimiento de las legalidades histórico-sociales, efectúa la superación de la teoría hegeliana de la enajenación. Para finalizar digamos que es esta profunda comprensión la que le ha permitido plasmar teóricamente la ruta de avance histórico más allá de la enajenación de la especie humana sólo posible bajo el socialismo, mientras que Hegel no ha podido en ningún momento escapar a una solución artificial e ilusoria.

\footnotetext{
${ }^{56}$ Marx, Obras de Marx.., 416.
}

57 Marx, Obras de Marx.., 417. 


\section{REFERENCIAS BIBLIOGRÁFICAS}

Adorno, Theodor. Tres estudios sobre Hegel (Madrid:Taurus Ediciones, 1974)

Bloch, Ernst. Sujeto-objeto: El pensamiento de Hegel (México: Fondo de Cultura Económica, 1982)

D'Honth, Jaques. Hegel, filósofo de la historia viviente (Buenos Aires: Amorrortu editores, 1966)

Eagleton, Terry. Por qué Marx tenía razón (Barcelona: Ediciones Península, 2011)

Engels, Federico. Anti-Dühring. La subversión de la ciencia por el señor Eugen Dúhring (México: Editorial Grijalbo, 1968)

Hegel, Georg. Ciencia de la lógica (Buenos Aires: Solar/Hachette, 1968) Escritos de juventud (México: Fondo de Cultura Económica, 1982)

Editorial, 1999)

Enciclopedia de las Ciencias Filosóficas, (Madrid: Alianza Fenomenología del Espíritu (México: Fondo de Cultura Económica, 1966)

Filosofía Real (Madrid: Fondo de Cultura Económica, 2006)

Heidegger, Martin. Carta sobre el Humanismo (Madrid: Alianza Editorial, 2000)

Editorial, 1992)

La fenomenología del espíritu de Hegel (Madrid: Alianza

Hyppolite, Jean. Génesis y estructura de la «Fenomenología del espíritu» (Barcelona: Ediciones Península, 1974)

Kaufmann, Walter. Hegel (Madrid:Alianza Editorial, 1968)

Lenin, Vladimir Ilich. Obras (Moscú: Editorial Progreso, 1983)

Löwy, Michael. La teoría de la revolución en el joven Marx, (Buenos Aires: Siglo XXI editores, 1972)

Marcuse, Herbert. Razón y revolución (Madrid: Ediciones Altaya, 1994) 
Marx, Carlos. Obras de Marx y Engels, OME V. 5 (Barcelona: Editorial Crítica, 1978) El Capital, T. I (México: Fondo de Cultura Económica, 1999) Elementos fundamentales para la Crítica de la Economía Política (México: Siglo XXI Editores, 2007)

Escritos de juventud (Madrid: Fondo de Cultura Económica, 1978)

Prieto, Fernando. El Pensamiento Político de Hegel (Madrid: UPCM, 1983)

Sánchez Vázquez, Adolfo. Filosofía de la praxis (México: Siglo XXI editores, 2003)

Taylor, Charles. Hegel y la sociedad moderna (México: Fondo de Cultura económica, 1983) 